\title{
Effects of Epichlö̈ festucae Fungal Endophyte Infection on Drought and Heat Stress Responses of Strong Creeping Red Fescue
}

\author{
Zipeng Tian, Bingru Huang, and Faith C. Belanger ${ }^{1}$ \\ Department of Plant Biology and Pathology, Rutgers University, 59 Dudley Road, New Brunswick, \\ NJ 08901
}

\begin{abstract}
Additional INDEX words. Festuca rubra, abiotic stress
Abstract. Strong creeping red fescue (Festuca rubra ssp. rubra) is an important cool season turfgrass species. Cultivars are often infected with the fungal endophyte Epichlö festucae. Endophyte infection is known to confer insect and disease resistance to the plants. The effect of endophyte infection on drought or heat stress tolerance of strong creeping red fescue is not yet established. The objectives of this controlled-environment study were to determine if endophyte infection had any effect on physiological parameters associated with plant tolerance to drought or heat stress or the combination of the two stresses. In this study, endophyte status had no effect on turf quality (TQ), relative water content (RWC), photochemical efficiency, chlorophyll content, electrolyte leakage (EL), or malondialdehyde (MDA) content of the plants under any of the stress treatments. Our results suggested that $E$. festucae infection had no physiological effects on improving drought, heat or the combined stress tolerance in strong creeping red fescue.
\end{abstract}

Epichloë species are fungal endophytes of many cool season grass species. The fungi exist exclusively in association with their plant hosts and the associations are considered to be mutualistic. Forty-three unique Epichloë taxa have been described, infecting numerous grass species (Leuchtmann et al., 2014). Likely additional species will be discovered in the future. The benefits of endophyte infection are often generalized as applying to all endophyte species-grass species associations, although there are many examples demonstrating that is not the case.

The plants provide nutrients to the endophytes and the endophytes provide tolerance to biotic and abiotic stresses to the plants, although the specific benefits vary among the many grass species/endophyte species combinations (Kuldau and Bacon, 2008). The best-characterized benefit to the plants is protection from predation by insects and mammals due to the production of toxic fungal alkaloids (Schardl et al., 2013). Endophyte mediated drought resistance in tall fescue (Lolium arundinaceum) and disease resistance in strong creeping red fescue and chewings fescue ( $F$. rubra ssp. commutata) are also well established (Bonos et al., 2005; Clarke et al., 2006; Malinowski and Belesky, 2000) although the underlying physiological mechanisms are not as well established.

Drought and heat are the most widespread abiotic stresses encountered by plants. Numerous studies have demonstrated that tall fescue infected with the fungal endophyte Epichloë coenophiala exhibits improved drought tolerance relative to endophyte-free plants (Kuldau and Bacon, 2008; Malinowski and Belesky, 2000, 2006; West, 1994). Both drought avoidance and drought tolerance mechanisms have been implicated in the effect of endophyte infection on tall fescue (Malinowski and

Received for publication 21 Jan. 2015. Accepted for publication 18 Mar. 2015. We thank the Rutgers Center for Turfgrass Science and USDA-NIFA Hatch for financial support. We also thank Mr. Patrick Burgess for technical assistance. ${ }^{1}$ Corresponding author. E-mail: belanger@aesop.rutgers.edu.
Belesky, 2000). In response to water stress, endophyte-infected tall fescue plants were found to accumulate higher levels of several compatible solutes than the endophyte-free plants, supporting osmotic adjustment as a component of the observed drought tolerance (Nagabhyru et al., 2013).

Although endophyte-mediated enhanced drought-tolerance is well established in tall fescue, reports on endophyte effects in other grass species are variable. In perennial ryegrass (Lolium perenne), infection with the endophyte E. festucae var. lolii has been reported to have no effect on vegetative tissues under drought conditions (Barker et al., 1997; Briggs et al., 2013; Cheplick et al., 2000; Hesse et al., 2005). Other studies have reported endophyte infection to be beneficial to perennial ryegrass under drought stress conditions (Amalric et al., 1999; Hahn et al., 2008; He et al., 2013; Ravel et al., 1997). Endophyte infection by an Epichloë species was reported to be beneficial to Arizona fescue (Festuca arizonica) and grove bluegrass (Poa alsodes) under conditions of low water availability (Kannadan and Rudgers, 2008; Morse et al., 2002). There are no studies on the effect of fungal endophyte infection on the responses of the host grass to sustained heat stress conditions in any species. In addition, little is known of endophyte effects on the combination of drought and heat stress, which often occurs during summer months in many areas.

Strong creeping red fescue is an important low maintenance turfgrass species (Ruemmele et al., 2003) and plants are often naturally infected with the fungal endophyte $E$. festucae (Schardl, 2001; Scott et al., 2012). Endophyte infection is preferred in strong creeping red fescue cultivar development because of the well-documented insect and disease resistance conferred on the host grass (Bonos et al., 2005; Clarke et al., 2006; Saha et al., 1987; Yue et al., 2000). Whether endophyte infection has a beneficial effect in strong creeping red fescue in responses to drought or heat stress has not been established. Therefore, the objectives of this study were to determine whether E. festucae has effects on strong 
creeping red fescue under heat stress, drought stress, and the combination of the two.

\section{Materials and Methods}

Plant materials and experimental design. The development of the plants used in this study was described previously (Johnson-Cicalese et al., 2000). These endophyte-infected plants have been stably maintained in the greenhouse through clonal propagation for over 15 years. Endophyte status was confirmed microscopically (Saha et al., 1988) before initiation of this study. The plants used were a strong creeping red fescue not infected with E. festucae (designated E-) and plants infected with two different isolates of $E$. festucae. The endophyte-infected plants were the E- plant genotype, designated S1139 (Johnson-Cicalese et al., 2000), inoculated with either the Rose City (RC) isolate or the Delaware (DE) isolate of E. festucae. The RC isolate was obtained from an endophyte-infected strong creeping red fescue plant and the DE isolate was obtained from an endophyte-infected chewings fescue. The endophyte-infected plants are thus the same plant genotype as the endophyte-free plant infected with two different isolates of E. festucae. Although strong creeping red fescue and chewings fescue are subspecies of F. rubra, they do not naturally hybridize (Ruemmele et al., 2003). In an amplified fragment length polymorphism analysis of many Epichlö isolates, the E. festucae isolates from strong creeping red fescue and chewings fescue grouped into separate clades, indicating the endophytes from these two distinct grass species are also distinct from each other (Tredway et al., 1999).

On 11 Mar. 2014, mature sod pieces from the greenhouse grown strong creeping red fescue plants were washed with water, and transplanted into 12 plastic boxes $(57 \mathrm{~cm}$ length $\times$ $44 \mathrm{~cm}$ width $\times 30 \mathrm{~cm}$ height) filled with fritted clay (Turface Green Grade; Profile Products, Buffalo Grove, and IL). Each box was divided into six equal spaces to separate the plant types. Six samples of $5 \mathrm{~cm}$ diameter were arranged randomly in one divider box. Plants were watered every other day, fertilized every week with half-strength Hoagland's solution, and trimmed every 3 weeks to $5 \mathrm{~cm}$ canopy height. The plants were maintained for $50 \mathrm{~d}$ in a greenhouse with an average temperature of $22 / 17{ }^{\circ} \mathrm{C}$ (day/night), $700 \mu \mathrm{mol} \cdot \mathrm{m}^{-2} \cdot \mathrm{s}^{-1}$ photosynthetically active radiation $(P A R)$ from natural sunlight, and $65 \%$ relative humidity to establish root and canopy systems. On 29 Apr. 2014, three boxes were moved into each of four controlled-climate growth chambers (Environmental Growth Chamber, Chargrin Falls, and $\mathrm{OH}$ ) set to $22 / 17{ }^{\circ} \mathrm{C}$ (day/night) temperature, $60 \%$ relative humidity, $650 \mu \mathrm{mol} \cdot \mathrm{m}^{-2} \cdot \mathrm{s}^{-1} P A R$, and a $14-\mathrm{h}$ photoperiod. Soil moisture was measured everyday to maintain soil water status using time domain reflectometry (6050X1 Trase SystemI; Soilmoisture Equipment Corp., Santa Barbara, CA). The plants were watered every other day for $6 \mathrm{~d}$ until the day before treatments started.

On 5 May 2014, the treatments were initiated. In each growth chamber there were three boxes. Each box contained a total of six plants, two samples of each of the three plant types, yielding a total of six replicates of each plant type for each treatment. Plants were exposed to four treatments applied in the different growth chambers: 1) in the control treatment, plants were well-watered, while the temperature of the growth chamber was kept $22 / 17^{\circ} \mathrm{C}$; 2) in the heat stress treatment, plants were well-watered, but the temperature of the growth chamber was kept $35 / 30^{\circ} \mathrm{C} ; 3$ ) in the drought stress treatment, water was withheld and the temperature was kept $22 / 17{ }^{\circ} \mathrm{C}$; 4) in the combination of heat and drought stress treatment, water was withheld and the temperature was kept $35 / 30{ }^{\circ} \mathrm{C}$.

Beginning on 2 June 2014, after 28 d of stress treatments, the plants were allowed to recover by returning the temperature to $22 / 17{ }^{\circ} \mathrm{C}$ (day/night) for all growth chambers and plants were watered every other day for $14 \mathrm{~d}$.

Physiological measurements. Turf quality, based on leaf color, density, and uniformity of turf, was rated on a 1-9 scale ( 1 = dead; 9 = fully turgid, green, and dense).

Leaf RWC was measured to evaluate leaf water status. To determine RWC, $0.1 \mathrm{~g}$ leaf tissues cut into 1-cm segments were collected and weighed immediately for fresh weight (FW). They were then soaked in deionized water for $24 \mathrm{~h}$ in fifty-milliliter centrifuge tubes, the tissues were then blotted dry with paper towels, and the turgid weight (TW) was measured. The samples were then dried in the oven at $80^{\circ} \mathrm{C}$ for $72 \mathrm{~h}$ and dry weight (DW) of tissues was measured. Relative water content was calculated as $(\mathrm{FW}-\mathrm{DW}) /(\mathrm{TW}-\mathrm{DW}) \times 100($ Barrs and Weatherley, 1962).

Leaf photochemical efficiency was determined as an indication of photosynthetic activity. It was expressed as the ratio of variable fluorescence to maximum fluorescence ( $\mathrm{Fv} / \mathrm{Fm})$, which was measured with a fluorescence induction monitor (BioScientific, Hoddesdon, UK).

Leaf chlorophyll content was measured to assess level of leaf chlorosis or senescence. To determine chlorophyll concentration, leaf tissue $(0.1 \mathrm{~g})$ was cut into $1-\mathrm{cm}$ segments and soaked in $10 \mathrm{~mL}$ dimethyl sulfoxide (DMSO) in the dark for at least $72 \mathrm{~h}$ (Hiscox and Israeltem, 1979). A 0.5-mL aliquot of the extract was mixed with $1 \mathrm{~mL}$ of DMSO and the absorbance at 645 and $663 \mathrm{~nm}$ was measured (Spectronic Instruments, Rochester, NY). Chlorophyll concentration was calculated as described by Arnon (1949).

Leaf EL was determined as the indication of cell membrane stability (Blum and Ebercon, 1981). For EL determinations, fresh leaf tissue $(0.2 \mathrm{~g})$ was cut into $1-\mathrm{cm}$ segments, rinsed with deionized water and shaken in $40 \mathrm{~mL}$ deioinized water on a conical flask shaker (Laboratory-Line Instruments, Melrose Park, IL) for $15 \mathrm{~h}$. The initial conductivity $\left(C_{\mathrm{i}}\right)$ was measured with a conductivity meter (model 32; YSI, Yellow Springs, $\mathrm{OH}$ ). The leaves were then killed by autoclaving at $121{ }^{\circ} \mathrm{C}$ for $20 \mathrm{~min}$. The solution was shaken for $15 \mathrm{~h}$ and then the final conductivity $\left(C_{\mathrm{f}}\right)$ was measured. EL was calculated as $C_{\mathrm{i}} / C_{\mathrm{f}} \times 100$.

Leaf membrane lipid peroxidation was evaluated by measuring the content of MDA, which is the final product of lipid peroxidation, following the procedure described in Dhindsa et al. (1981). For determination of MDA content, frozen leaf tissue $(0.25 \mathrm{~g})$ was ground into a powder with liquid nitrogen and placed into $2 \mathrm{~mL} 0.1 \%$ trichloroacetic acid (TCA). The samples were centrifuged at 12,000 $g_{n}$ for $15 \mathrm{~min}$ and $1 \mathrm{~mL}$ of the supernatant was mixed with $4 \mathrm{~mL}$ reaction solution containing TCA and thiobarbituric acid $(40: 1, \mathrm{v} / \mathrm{v})$. The samples were heated in an incubator at $95^{\circ} \mathrm{C}$ for $30 \mathrm{~min}$ then cooled quickly in an ice water bath. The samples were again centrifuged at $12,000 \mathrm{~g}_{\mathrm{n}}$ for $15 \mathrm{~min}$. The absorbance of the supernatant at 532 and $600 \mathrm{~nm}$ was 
Table 1. Analysis of variance of effect of Epichloë festucae fungal endophyte infection on strong creeping red fescue responses to the heat, drought, and heat + drought stress treatments.

\begin{tabular}{lcccccc}
\hline & Turf quality & Relative water content & Fv/Fm ${ }^{z}$ & Chlorophyll content & Electrolyte leakage & MDA content \\
\hline Endophyte & NS & $*$ & NS & $*$ & $* *$ & $* *$ \\
Treatment & $* * *$ & $* * *$ & $* * *$ & $* * *$ & $* *$ & $* *$ \\
Endophyte $\times$ treatment & NS & NS & NS & NS & $* *$ & NS \\
\hline
\end{tabular}

$\overline{{ }^{\mathrm{z}} \mathrm{Fv} / \mathrm{Fm}}=$ photochemical efficiency; MDA $=$ malondialdehyde.

Ns, $* * *, * * *$ nonsignificant or significant at $P \leq 0.05,0.01$, or 0.001 , respectively.

measured. The value for the nonspecific absorption at $600 \mathrm{~nm}$ was subtracted from the $523 \mathrm{~nm}$ reading. The MDA concentration was calculated using the extinction coefficient of $155 \mathrm{mM}^{-1} \cdot \mathrm{cm}^{-1}$ (Heath and Packer, 1968).

Statistical analysis. This experiment was a completely randomized block design. Each of the four growth chambers was considered a single block. Statistical significance was tested using the analysis of variance procedure (ANOVA) in SAS (version 9.3; SAS Institute, Cary, NC). Differences between treatments were separated by Fisher's protected least significance difference (LSD) test at the $0.05 P$ level. Bonferroni posttests were carried out on the data for each treatment at each rating date to compare the data from each of the endophyteinfected plants to that of the endophyte-free plants by using the PRISM 4 program (GraphPad Software, San Diego, CA).

\section{Results}

There were similar trends in turf appearance, TQ ratings, and RWC among the endophyte-free, RC endophyte-infected, and DE endophyte-infected plants in response to heat, drought, and heat + drought stresses (Table 1; Figs. 1-3). None of the data for TQ and RWC of the endophyte-infected plants was significantly different from the endophyte-free plants except the $14 \mathrm{~d}$ RWC, which was lower for the endophyte-infected plants. The stress treatments had similar effects on all plant types. Heat stress had no significant effect on overall appearance, TQ rating, and RWC. Drought and the combination of heat and drought resulted in reductions in appearance, TQ rating and RWC. The appearance, TQ and the RWC of both heat-stressed and drought-stressed plants recovered when returned to control conditions. However, heat + droughtstressed plants did not recover by one week after cessation of the stress.

Endophyte infection had no significant effects on leaf $\mathrm{Fv} / \mathrm{Fm}$ in the responses to the stress treatments. Fv/Fm was unaffected by heat or drought stress treatments for any of the plant types and was maintained at about 0.8 throughout the stress treatment (Fig. 4). However, Fv/Fm was severely affected by the combination of heat + drought stress, which declined to below 0.1 at $28 \mathrm{~d}$ of stress in all three plant types.

Leaf chlorophyll levels showed similar responses to the stresses in all three plant types (Fig. 5). Only the $21 \mathrm{~d}$ level in the DE endophyte-infected plant was significantly different from the endophyte-free plants. The chlorophyll levels of the heat + drought-stressed plants of all three plant types were most severely affected and did not recover after cessation of the stress.

None of the data for EL of the endophyte-infected plants was significantly different from the endophyte-free plants except the 14-d measurement in response to the heat + drought stress, which was higher for the endophyte-infected plants. EL was unaffected by heat stress or drought stress in all three plant types (Fig. 6). However, the combination of heat + drought stress resulted in a large increase in EL, up to about $80 \%$ by $28 \mathrm{~d}$ of stress in all three plant types. After $7 \mathrm{~d}$ of recovery from the stress, EL was reduced from its peak, but was still at about $65 \%$.

Similar trends of MDA content were found in all three plant types in response to the stresses and there were no significant differences in MDA content between the endophyte free plants and endophyte-infected plants under drought, heat, or the combined heat + drought stress (Fig. 7). The endophyte significant difference detected by the ANOVA analysis was the difference between the $\mathrm{RC}$ and $\mathrm{DE}$ endophyte-infected 

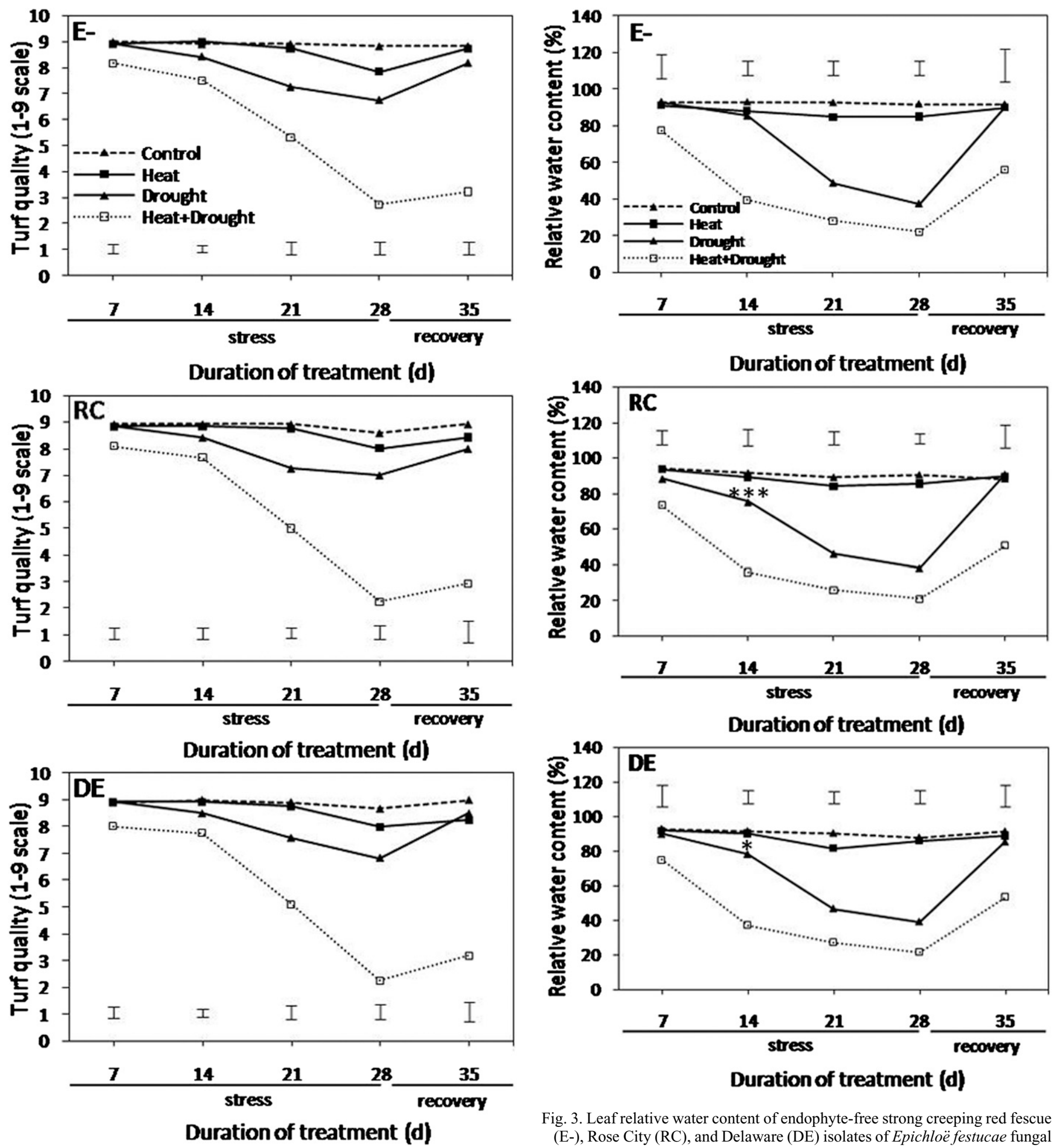

Fig. 2. Turf quality ratings $(1=$ dead; $9=$ fully turgid, green, and dense $)$ of endophyte-free strong creeping red fescue (E-), Rose City (RC), and Delaware (DE) isolates of Epichlö festucae fungal endophyte-infected strong creeping red fescue plants in response to heat, drought, and heat + drought stress. Vertical bars are least significant difference values $(P \leq 0.05)$ for treatment comparisons of each plant type at a given day of treatment.

plants at $21 \mathrm{~d}$ of heat + drought stress. Heat-stressed plants had similar MDA contents as the control plants throughout the duration of the test. Drought-stressed plants had increased MDA levels at $28 \mathrm{~d}$ of stress, whereas the heat + drought-stressed

Fig. 3. Leaf relative water content of endophyte-free strong creeping red fescue (E-), Rose City (RC), and Delaware (DE) isolates of Epichloë festucae fungal endophyte-infected strong creeping red fescue plants in response to heat, drought, and heat + drought stress. Significant differences between the RC and DE endophyte-infected plants, each relative to the endophyte free plants, are indicated by $* * *(P<0.001)$ and $*(P<0.05)$. Vertical bars are least significant difference values $(P \leq 0.05)$ for treatment comparisons of each plant type at a given day of treatment.

plants began to show increased MDA levels by $14 \mathrm{~d}$ of stress. The MDA levels of the drought-stressed plants returned to control levels by $7 \mathrm{~d}$ of recovery but those of the heat + droughtstressed plants did not. 

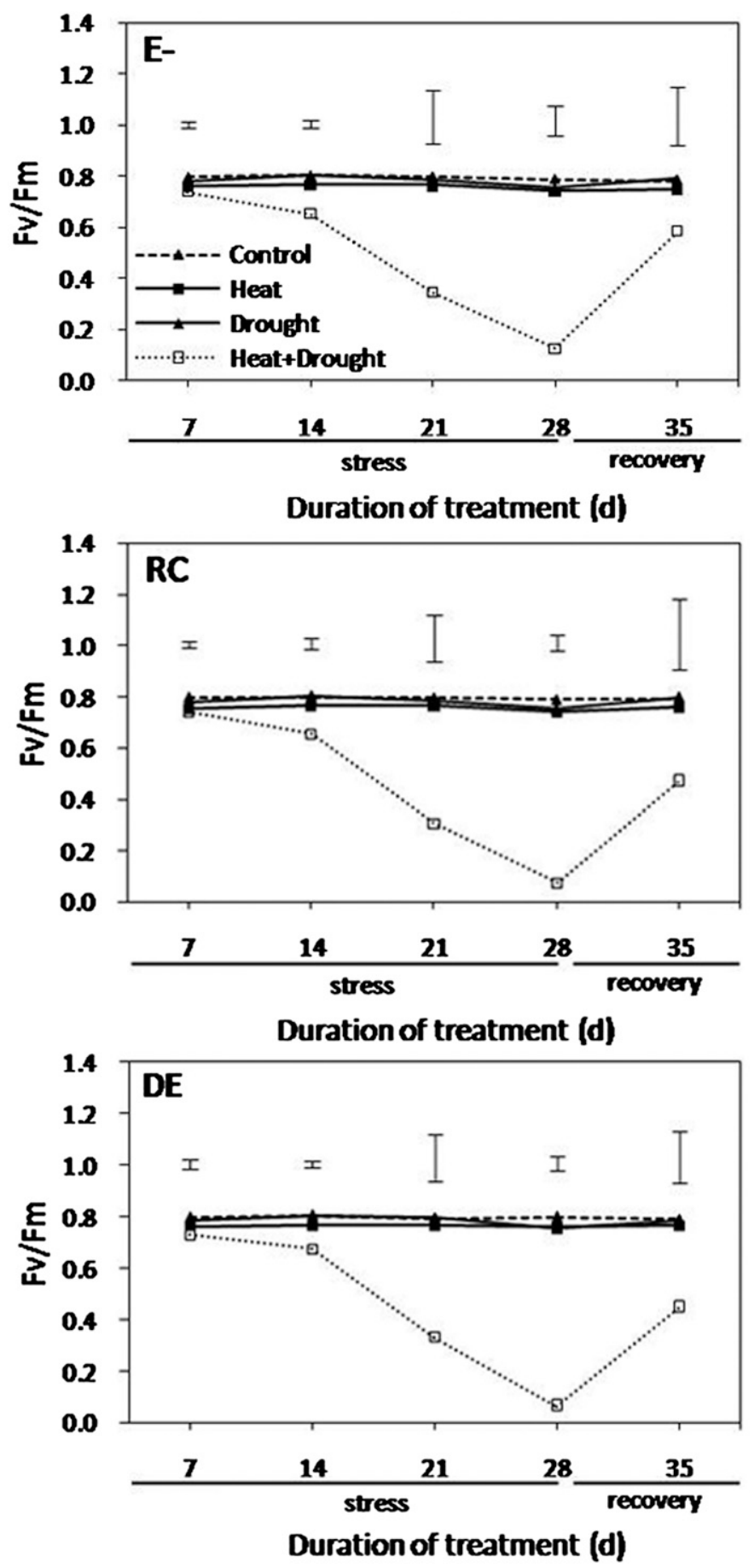

Fig. 4. Photochemical efficiency ( $\mathrm{Fv} / \mathrm{Fm})$ of endophyte-free strong creeping red fescue (E-), Rose City (RC), and Delaware (DE) isolates of Epichloë festucae fungal endophyte-infected strong creeping red fescue plants in response to heat, drought, and heat + drought stress. Vertical bars are least significant difference values $(P \leq 0.05)$ for treatment comparisons of each plant type at a given day of treatment.

\section{Discussion}

The beneficial effects of E. festucae fungal endophyte infection on strong creeping red fescue regarding insect and fungal disease tolerance are well established (Bonos et al., 2005; Clarke et al., 2006; Saha et al., 1987; Yue et al., 2000).
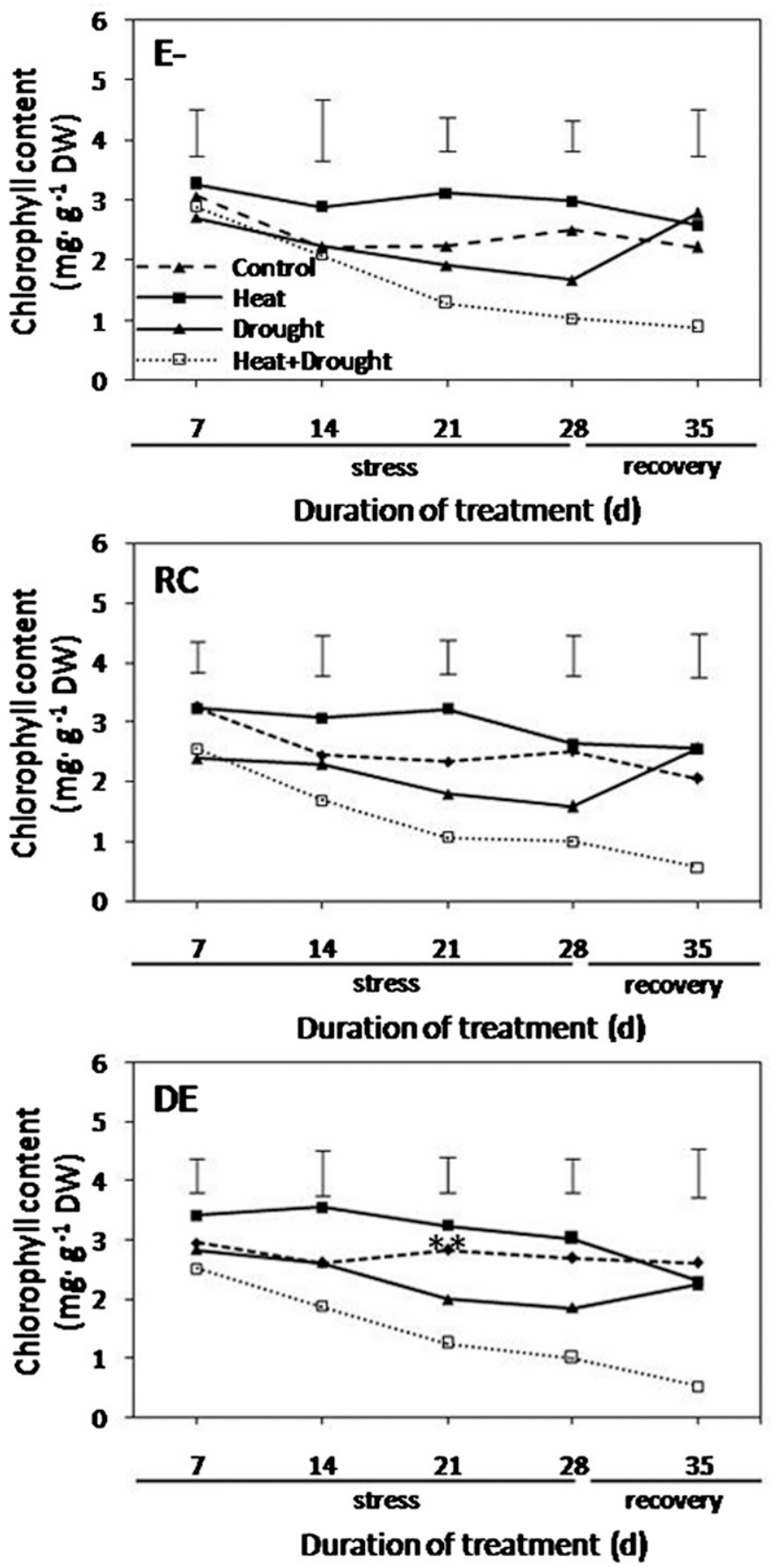

Fig. 5. Chlorophyll content of endophyte-free strong creeping red fescue (E-), Rose City (RC), and Delaware (DE) isolates of Epichloë festucae fungal endophyte-infected strong creeping red fescue plants in response to heat, drought, and heat + drought stress. Significant difference between the DE endophyte-infected plants, relative to the endophyte-free plants, is indicated by $* *(P<0.01)$. Vertical bars are least significant difference values $(P \leq$ 0.05 ) for treatment comparisons of each plant type at a given day of treatment.

However, the effect of E. festucae infection on abiotic stress tolerance of strong creeping red fescue has not been well studied. Only one previous study has addressed the effect of $E$. festucae infection of $F$. rubra during drought stress and concluded that endophyte infection did not increase drought tolerance (Vázquez-de-Aldana et al., 2013). Here we have 

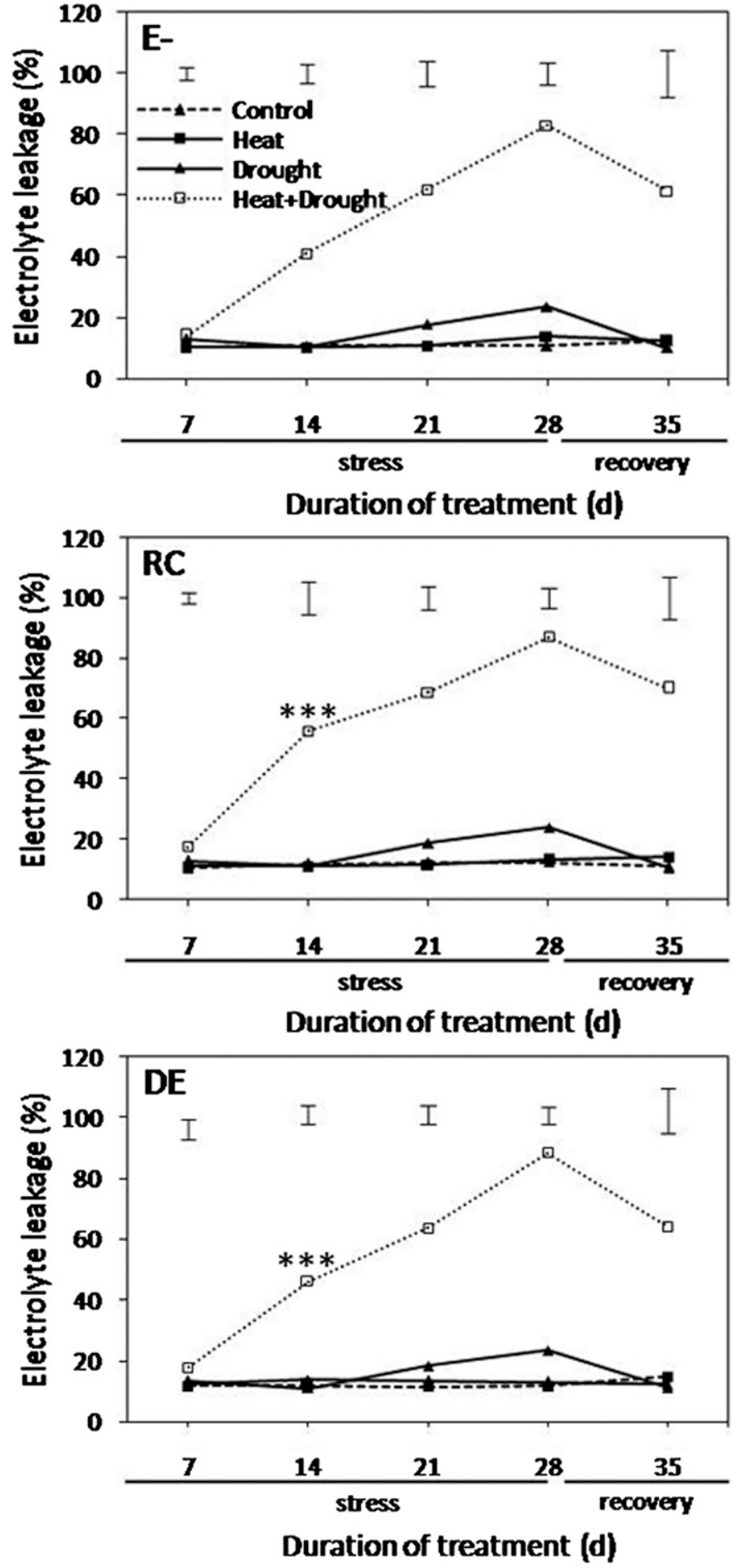

Fig. 6. Electrolyte leakage of endophyte-free strong creeping red fescue (E-), Rose City (RC), and Delaware (DE) isolates of Epichloë festucae fungal endophyte-infected strong creeping red fescue plants in response to heat, drought, and heat + drought stress. Significant differences between the RC and DE endophyte-infected plants, each relative to the endophyte free plants, are indicated by $* * *(P<0.001)$. Vertical bars are least significant difference values $(P \leq 0.05)$ for treatment comparisons of each plant type at a given day of treatment.

determined the effect of drought stress, heat stress, and the combination of heat + drought stress on TQ, RWC, Fv/Fm, chlorophyll content, EL, and MDA content of endophyte-free and endophyte-infected strong creeping red fescue. Overall, in
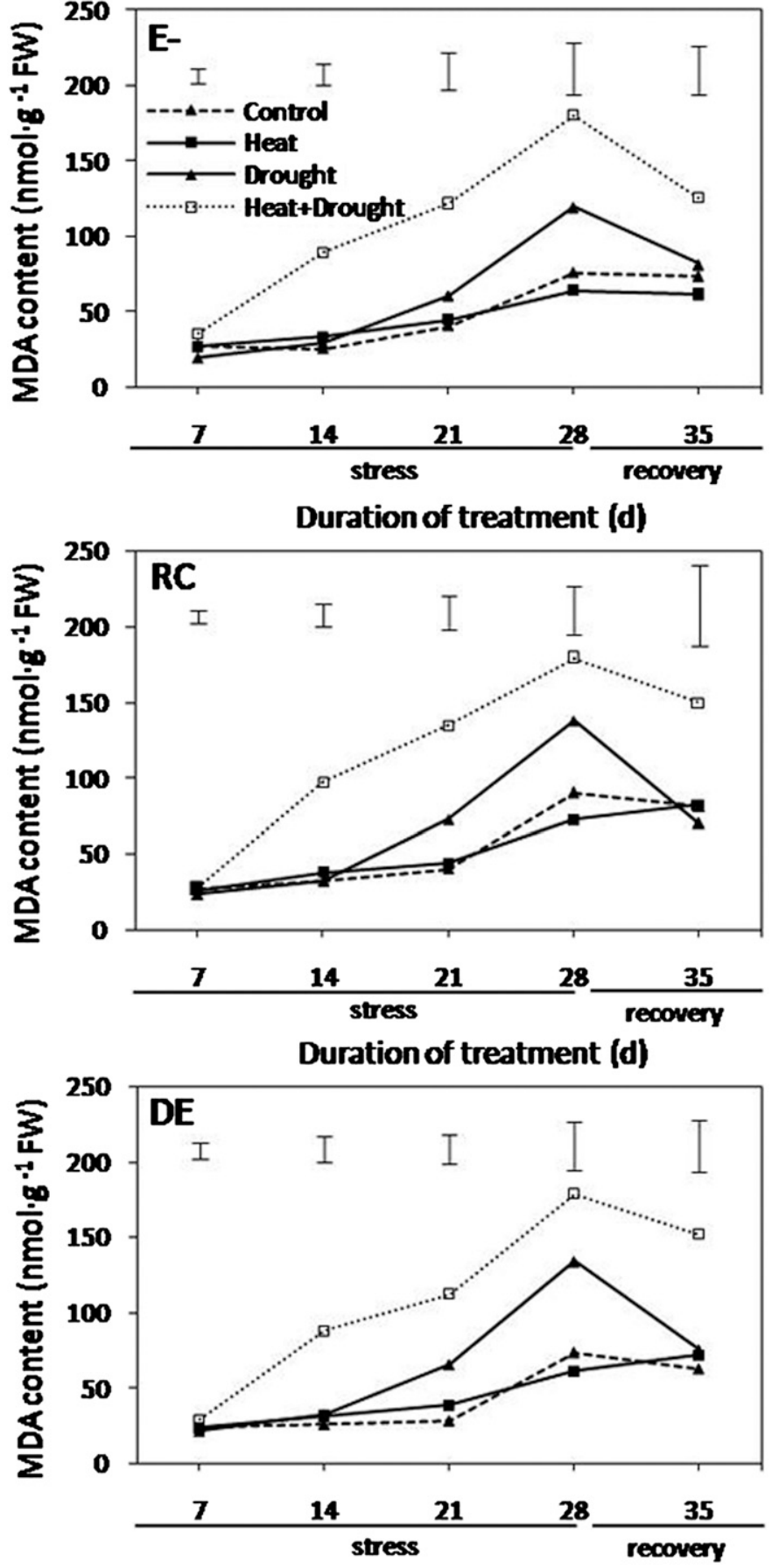

Duration of treatment (d)

Fig. 7. Malondialdehyde (MDA) content of endophyte-free strong creeping red fescue (E-), Rose City (RC), and Delaware (DE) isolates of Epichloë festucae fungal endophyte-infected strong creeping red fescue plants in response to heat, drought, and heat + drought stress. Vertical bars are least significant difference values $(P \leq 0.05)$ for treatment comparisons of each plant type at a given day of treatment.

this study, endophyte status had no effect on the physiological responses of the plants to any of the stress conditions. The endophyte-mediated drought tolerance seen in some Epichlö̈ species-grass species combinations, particularly tall fescue infected with E. coenophiala, was not observed in strong creeping red fescue infected with $E$. festucae. 
Strong creeping red fescue is generally considered to have good drought tolerance but to have poor heat tolerance (Grimshaw et al., 2014; Ruemmele et al., 2003). Our data indicate that drought tolerance of strong creeping red fescue is not related to endophyte infection. Even at $28 \mathrm{~d}$ of drought stress, the plants were just beginning to show visible symptoms of stress, such as leaf wilting, and on cessation of stress could fully recover. In contrast to the general perception that fine fescues have poor heat tolerance, under well-watered conditions the plants in this study showed good heat tolerance to $35^{\circ} \mathrm{C}$. Only slight wilting was observed, even after $28 \mathrm{~d}$ of high temperature. However, the combination of heat + drought stress caused severe damage to the plants and they were not able to fully recover on cessation of the stress conditions. A similar dramatic detrimental effect of the combined stresses of drought and heat was seen in kentucky bluegrass (Poa pratensis), tall fescue, and perennial ryegrass (Jiang and Huang, 2000, 2001; $\mathrm{Yu}$ et al., 2012). The results reported here suggest that the combined drought and heat stress was more detrimental than either drought or heat stress alone for strong creeping red fescue, and adequate irrigation of strong creeping red fescue during summer may be able to mitigate the severe damage observed with the combined stresses. In addition, endophyte infection provided no benefits of promoting plant tolerance to drought, heat, or the combined stress in strong creeping red fescue.

\section{Literature Cited}

Amalric, C., H. Sallanon, F. Monnet, A. Hitmi, and A. Coudret. 1999. Gas exchange and chlorophyll fluorescence in symbiotic and nonsymbiotic ryegrass under water stress. Photosynthetica 37:107-112. Arnon, D.I. 1949. Copper enzyme in isolated chIoroplasts. Polyphenoloxidase in Beta vulgaris. Plant Physiol. 24:1-15.

Barker, D.J., D.E. Hume, and P.E. Quigley. 1997. Negligible physiological responses to water deficit in endophyte-infected and uninfected perennial ryegrass, p. 137-140. In: N.S. Hill and C.W. Bacon (eds.). Neotyphodium/grass interactions. Plenum Press, New York, NY.

Barrs, H.D. and P.E. Weatherley. 1962. A re-examination of the relative turgidity technique for estimating water deficit in leaves. Austral. J. Biol. Sci. 15:413-428.

Blum, A. and A. Ebercon. 1981. Cell membrane stability as a measure of drought and heat tolerance in wheat. Crop Sci. 21:43-47.

Bonos, S.A., M.M. Wilson, W.A. Meyer, and C.R. Funk. 2005. Suppression of red thread in fine fescues through endophytemediated resistance. Appl. Turfgrass Sci. 10:1094.

Briggs, L., J. Crush, L. Ouyang, and J. Sprosen. 2013. Neotyphodium endophyte strain and superoxide dismutase activity in perennial ryegrass plants under water deficit. Acta Physiol. Plant. 35:1513-1520.

Cheplick, G.P., A. Perera, and K. Koulouris. 2000. Effect of drought on the growth of Lolium perenne genotypes with and without fungal endophytes. Funct. Ecol. 14:657-667.

Clarke, B.B., J.F. White, Jr., R.H. Hurley, M.S. Torres, S. Sun, and D.R. Huff. 2006. Endophyte-mediated suppression of dollar spot disease in fine fescues. Plant Dis. 90:994-998.

Dhindsa, R.S., P.P. Dhindsa, and T.A. Thorpe. 1981. Leaf senescence: Correlation with increased levels of membrane permeability and lipid peroxidation, and decreased levels of superoxide dismutase and catalase. J. Expt. Bot. 32:93-101.

Grimshaw, A., T.M. Tate, D.A. Smith, R.F. Bara, M.M. Mohr, E.N. Weibel, S.A. Bonos, and W.A. Meyer. 2014. Performance of fine fescue cultivars and selections in New Jersey turf trials. Rutgers Turfgrass Proc. 45:47-79.

Hahn, H., M.T. McManus, K. Warnsstorff, B.J. Monahan, C.A. Young, E. Davies, B.A. Tapper, and B. Scott. 2008. Neotyphodium fungal endophytes confer physiological protection to perennial ryegrass (Lolium perenne L.) subjected to a water deficit. Environ. Expt. Bot. 63:183-199.

He, L., J.-H.B. Hatier, S.D. Card, and C. Matthew. 2013. Endophyteinfection reduces leaf dehydration of ryegrass and tall fescue plants under moderate water deficit. Proc. N.Z. Grassland Assn. 75:151-156.

Heath, R.L. and L. Packer. 1968. Photoperoxidation in isolated chloroplasts. I. Kinetics and stoichiometry of fatty acid peroxidation. Arch. Biochem. Biophys. 125:189-198.

Hesse, U., W. Schoberlein, L. Wittenmayer, K. Forster, K. Warnstorff, W. Diepenbrock, and W. Merbach. 2005. Influence of water supply and endophyte infection (Neotyphodium) on vegetative and reproductive growth of two Lolium perenne L. genotypes. Eur. J. Agron. 22:45-54.

Hiscox, J.D. and G.F. Israeltem. 1979. A method for the extraction of chlorophyll from leaf tissue without maceration using dimethyl sulfofxide. Can. J. Bot. 57:1332-1334.

Jiang, Y. and B. Huang. 2000. Effects of drought or heat stress alone and in combination on kentucky bluegrass. Crop Sci. 40:1358-1362.

Jiang, Y. and B. Huang. 2001. Physiological responses to heat stress alone or in combination with drought: A comparison between tall fescue and perennial ryegrass. HortScience 36:682-686.

Johnson-Cicalese, J., M.E. Secks, C.K. Lam, W.A. Meyer, J.A. Murphy, and F.C. Belanger. 2000. Cross species inoculation of chewings and strong creeping red fescues with fungal endophytes. Crop Sci. 40:1485-1489.

Kannadan, S. and J.A. Rudgers. 2008. Endophyte symbiosis benefits a rare grass under low water availability. Funct. Ecol. 22:706-713.

Kuldau, G. and C. Bacon. 2008. Clavicipitaceous endophytes: Their ability to enhance resistance of grasses to multiple stresses. Biol. Control 46:57-71.

Leuchtmann, A., C.W. Bacon, C.L. Schardl, J.F. White, and M. Tadych. 2014. Nomenclatural realignment of Neotyphodium species with genus Epichlö̈. Mycologia 106:202-215.

Malinowski, D.P. and D.P. Belesky. 2000. Adaptations of endophyteinfected cool-season grasses to environmental stresses: Mechanisms of drought and mineral stress tolerance. Crop Sci. 40:923-940.

Malinowski, D.P. and D.P. Belesky. 2006. Ecological importance of Neotyphodium spp. grass endophytes in agroecosystems. Grassland Sci. 52:1-14.

Morse, L.J., T.A. Day, and S.H. Faeth. 2002. Effect of Neotyphodium endophyte infection on growth and leaf gas exchange of arizona fescue under contrasting water availability regimes. Environ. Expt. Bot. 48:257-268.

Nagabhyru, P., R.D. Dinkins, C.L. Wood, C.W. Bacon, and C.L. Schard1. 2013. Tall fescue endophyte effects on tolerance to waterdeficit stress. BMC Plant Biol. 13:127.

Ravel, C., C. Courty, A. Coudret, and G. Charmet. 1997. Beneficial effects of Neotyphodium lolii on the growth and the water status in perennial ryegrass cultivated under nitrogen deficiency or drought stress. Agronomie 17:173-181.

Ruemmele, B.A., J.K. Wipff, L. Brilman, and K.W. Hignight. 2003. Fine-leaved Festuca species, p. 129-174. In: M.D. Cassler and R.R. Duncan (eds.). Turfgrass biology, genetics, and breeding. Wiley, Hoboken, NJ.

Saha, D.C., J.M. Johnson-Cicalese, P.M. Halisky, M.I. Van Heemstra, and C.R. Funk. 1987. Occurrence and significance of endophytic fungi in the fine fescues. Plant Dis. 71:1021-1024.

Saha, D.C., M.A. Jackson, and J.M. Johnson-Cicalese. 1988. A rapid staining method for detection of endophytic fungi in turf and forage grasses. Phytopathology 78:237-239.

Schardl, C.L. 2001. Epichloë festucae and related mutualistic symbionts of grasses. Fungal Genet. Biol. 33:69-82.

Schardl, C.L., C.A. Young, U. Hesse, S.G. Amyotte, K. Andreeva, P.J. Calie, D.J. Fleetwood, D.C. Haws, N. Moore, B. Oeser, D.G. Panaccione, K.K. Schweri, C.R. Voisey, M.L. Farman, J.W. Jaromczyk, B.A. Roe, D.M. O’Sullivan, B. Scott, P. Tudzynski, Z. An, E.G. Arnaoudova, C.T. Bullock, N.D. Charlton, L. Chen, 
M. Cox, R.D. Dinkins, S. Florea, A.E. Glenn, A. Gordon, U. Güldener, D.R. Harris, W. Hollin, J. Jaromczyk, R.D. Johnson, A.K. Khan, E. Leistner, A. Leuchtmann, C. Li, J. Liu, J. Liu, M. Liu, W. Mace, C. Machado, P. Nagabhyru, J. Pan, J. Schmid, K. Sugawara, U. Steiner, J.E. Takach, E. Tanaka, J.S. Webb, E.V. Wilson, J.L. Wiseman, R. Yoshida, and Z. Zeng. 2013. Plant-symbiotic fungi as chemical engineers: Multi-genome analysis of the Clavicipitaceae reveals dynamics of alkaloid loci. PLoS Genet. 9(2):e1003323.

Scott, B., Y. Becker, M. Becker, and G. Cartwright. 2012. Morphogenesis, growth, and development of the grass symbiont Epichloë festucae, p. 243-264. In: J. Perez-Martin and A. Di Pietro (eds.). Morphogenesis and pathogenicity in fungi. Springer-Verlag, Berlin, Germany.

Tredway, L.P., J.F. White, Jr., B.S. Gaut, P.V. Reddy, M.D. Richardson, and B.B. Clarke. 1999. Phylogenetic relationships within and between Epichloë and Neotyphodium endophytes as estimated by AFLP markers and rDNA sequences. Mycol. Res. 103:1593-1603. Vázquez-de-Aldana, B.R., A. García-Ciudad, B. García-Criado, S. Vicente-Tavera, and I. Zabalgogeazcoa. 2013. Fungal endophyte (Epichlö festucae) alters the nutrient content of Festuca rubra regardless of water availability. PLoS ONE 8:e84539.

West, C.P. 1994. Physiology and drought tolerance of endophyte-infected grasses, p. 87-99. In: C.W. Bacon and J.F. White, Jr. (eds.). Biotechnology of endophytic fungi of grasses. CRC Press, Boca Raton, FL. $\mathrm{Yu}$, J., L. Chen, M. Xu, and B. Huang. 2012. Effects of elevated $\mathrm{CO}_{2}$ on physiological responses of tall fescue to elevated temperature, drought stress, and the combined stresses. Crop Sci. 52:1848-1858.

Yue, Q., J. Johnson-Cicalese, T.J. Gianfagna, and W.A. Meyer. 2000. Alkaloid production and chinch bug resistance in endophyte-inoculated chewings and strong creeping red fescues. J. Chem. Ecol. 26:279-292. 